\title{
Muhasebe Hizmeti Alan Mükelleflerin Kişilik Özelliklerinin Müşteri Bağlılığı İle İlişkisi
}

\author{
DOI: 10.26466/opus.612220
}

\author{
* \\ Dursun Boz ${ }^{*}$ - İbrahim Kardaş ${ }^{* *}$ - Ali Altınbay ${ }^{* * *}$ \\ * Dr, Dumlupınar Üniversitesi, İ̈BF. İşletme / Kütahya / Türkiye \\ E-Posta: dursunboz@hotmail.com \\ ORCID: 0000-0003-3206-8950 \\ ** Bilim Uzmanı, Dumlupınar Üniversitesi, İ̈BF.İşletme / Kütahya/ Türkiye \\ E-Posta: ibrahimkardas43@hotmail.com \\ ORCID: 0000-0003-3039-8411 \\ *** Dr.Öğr.Üyesi, Dumlupınar Üniversitesi, İ̈BF. İşletme / Kütahya/ Türkiye \\ E-Posta: ali.altinbay@dpu.edu.tr \\ ORCID: 0000000331280669
}

\section{$\ddot{O} z$}

Son zamanlarda yapılan pek çok çalışma insanı anlamaya çalışmaktadır. Bu çalışmalar özünde insanın tutum ve davranışların analiz etmeye çalışmaktadır. Örgütsel bazda düşünüldü̈̆̈̈̈nde çalışanların tutum ve davranışları örgütsel hedef ve amaçlara ulaşmada başat rol üstlenmektedir. Enneagram kişilik özellikleri insanın tutum ve davranışlarının anlaşılmasında kullanılmaktadır. İşletmeler hem çalışanlarını hem de tüketicileri bir zincirin halkası gibi gördüklerinde başarıyı yakalayabileceklerdir. Yapılan bu çalışmanın amacı Enneagram kişilik özellikleri ile Müşteri Bağhlı̆̆̆ arasındaki ilişkinin belirlenmesidir. Bu amaçla Kütahya ili Serbest Muhasebeci ve Mali Müşavirler Odası'na kayıtlı muhasebecilerden hizmet alan 201 mükellefe gönüllülük esasına göre ulaşılmıştır. Enneagram yakın zamanda hem sosyal medyada hem de akademide sıkça duyduğumuz kavramlardan olmaya başladı. Müşteri bağlılığı ise pazarlamacıların sıklıkla üzerinde durdukları bir kavram olmayı sürdürmektedir. Elde ettiğimiz bulgularla Enneagram kişilik özellikleri ile Müşteri Bağhllı̆̆ı arasında çok zayıf-zayıf ve orta düzeyde ilişkileri tespit edilmiştir. Ayrıca Enneagram kişilik özelliklerinin hem Müşteri Bağhllı$\breve{g}$ ını hem de alt faktörlerini etkilediği tespit edilmiştir. Müşteri Bağglılığı ile en yüksek korelasyon "Tip7 Maceracı" ile iken en düşük korelasyon ise "Tip-2 Yardımcı" ile olduğu tespit edilmiştir.

Anahtar Kelimeler: Enneagram, Müşteri Bağhllı̆̆ı, Mükellef 


\title{
Relationship of Personality Characteristics of Taxpayers With Customer Loyalty
}

\begin{abstract}
Many recent studies have tried to understand people. In essence, these studies try to analyze human attitudes and behaviors. When considering the organizational basis, the attitudes and behaviors of the employees play an important role in achieving the organizational goals and objectives. Enneagram personality traits are used to understand human attitudes and behaviors. Businesses will be able to capture success when they see both their employees and consumers as the ring of a chain. The aim of this study is to determine the relationship between Enneagram and Customer Loyalty. For this purpose, the 201 taxpayer who received accounting services from certified public accountant and financial advisor in Kütahya province was reached on a voluntary basis. Enneagram has recently become one of the concepts we often hear on both social media and academia. Customer loyalty remains a concept that marketers often emphasize. Our findings revealed very weak-weak and moderate relationships between Enneagram personality traits and customer loyalty. In addition, Enneagram personality traits have been found to affect both Customer Loyalty and its sub-factors. The highest correlation with customer loyalty was found to be with "Type-7 adventurer" while the lowest correlation was with "Type-2 helper".
\end{abstract}

Keywords: Enneagram, Customer Loyalty, Taxpayer 


\section{Giriş}

Tarih boyunca insanların tutum ve davranışlarını anlamaya çalışan birçok düşünür ve araştırmacı olmuştur. Bu düşünür ve araştırmacılar çeşitli kişilik ve mizaç özellikleri üzerinden insanları kategorize etmeye çalışmışlardır. Hipokrat'tan Mevlana'ya, Maslow'dan Freud'a kadar birçok araştırmacı konuyla ilgili çalışmalar yapmıştır. Bu çalışmalar geçmişten günümüze insanları çeşitli tipolojiler üzerinden tanımlamışlardır. İnsanların kişilik tipolojilerinin bilinmesi birey ve toplum açısından avantajlar sağlamaktadır. İlk olarak kendini tanıyan insan, nelerin hoşuna gittiğini nelerin gitmediğini bildiğinde üzerinde oluşabilecek stres kaynaklarına karşı kendini koruyabilmektedir. Kendini tanıyan birey çevresini de tanımaya başlayacaktır. Bu durumda iş, eş, aş seçiminde çeşitli avantajlar sağlayabilecektir. Kökeni M.Ö. 2500'li yıllara dayanan Enneagram da insan tipolojisini 9 ayrı şekilde tanımlamaktadır. Enneagram kişilik tipolojileri de insanın duygu, düşünce ve davranışlaryyla olası psikolojik temelli tepkilerinin anlaşılmasında önemli rol oynamaktadır. İnsanın fizyolojik ve zihinsel özelliklerinin kendi çevresiyle kuracağı iletişimde diğer insanlardan farklılaşmasını anlamaya çalışmaktadır.

Müşteri bağlllı̆̆g ise tüketici istek ve beklentilerinin anlaşılmasında anahtar rol üstlenmektedir. Küreselleşme ve ileri teknolojilerin gelişmesiyle oluşan rekabet neticesinde artık işletmeler ürettiklerini satan işletmeler olmaktan ziyade tüketicilerin istek ve beklentilerinin ötesinde ürün/hizmet üreten işletme olmak zorunda kalmıştır. Bu rekabette müşteri bağlılığ1 hali hazırdaki müşteriler, işletmenin ürün/hizmetlerine yönelik politikalar geliştirmeye zorlamıştır.

\section{Enneagram}

Kişilik ve mizaç, insanlık tarihi boyunca insan davranışlarını anlamaya ve açıklamaya çalışan araştırmacıların ilgi odağı olmuştur. Hipokrat'tan günümüz araştırmacılarına kadar kişilik ve mizaç üzerinde kuramlar geliştirilerek değişik sınıflamalar yapılmıştır (Clark, 2005, s.506). Bu sınıflandırmalar üzerindeki en önemli çalışmalar aydınlanma çağıyla başlayan, insanı psiko-sosyal açıdan inceleyip tutum ve davranışlarının anla- 
şılmasına çalışan kuramlardır. Psikoloji bilimi pek çok kişilik teorisi bulundurmakla birlikte yaygın olarak Freud'un psikoanalitik kuramı, Cattell ve Norton'un özellikler kuramı, Maslow ve Rogers'ın benlik kuramı, Erikson ve Jung'un sosyo-psikolojik kuramın sıklikla incelemektedir (İnanç ve Yerlikaya, 2002, s.54). Bu bağlamda Enneagram, eski bilge geleneklere dayanarak bu geleneklerin modern bir senteziyle oluşturulmuş; insan psikolojisindeki değişik özellik ve işlevleri farklı sistematik kişilik tipleri üzerinden tanımlayıp irdelemeye çalışan yeni bir kişilik modelidir (Pesen, 2015, s.40).

İnsanın yürüdüğü yolda kendi gerçeklerini bulması, insan olarak kendini ifade ederken ve diğer insanlar ile sağlıklı iletişim kurması için öncelikle kendisini tanımalıdır. Bu tanılamada enneagram, hayat boyu kendimizi keşif yolculuğunda tipimizle ilgili tuzakları ve zaafları gösterip, kendi özümüze derinden bakışı sağlar. Bu bakışla otomatik tepkilere dur diyerek, içgörü kazanmamıza yardım ederek uykuda yaşamak yerine uyanmamızı sağlar. Kişiliğimizin otomatik tepkilerini ne kadar sık görürsek, onlar ile özdeşleşmekten o sıklıkla vazgeçeriz. İnsanın kendisi olması ve özgürleşmesi böyle ifade edilmektedir (Palmer, 2006, s.12-14). Kişilik tipinin bilinmesi, hem birey hem de kendisiyle temas edecek olan bireyler için önemli bir avantajdır. İlk olarak kendini tanıması gereken birey, hangi tür şeylerden hoşlandığını veya hoşlanmadığını bilmeli ve üzerine stres oluşturan stres kaynakları ile daha iyi başa çıkabilmelidir. Birey, kendi niteliklerine göre profesyonel seçimler yaparak onu bekleyen olası psikolojik rahatsızlıklar için önlem alabilir. Bireyin kişilik tipini bilmekle onunla iletişimi kolaylaştırarak insanlar arasında pozitif yönlü bir diyaloga yol açabilir (Taştan, 2019, s.113).

Kökü M.Ö. 2500'lü yıllara dayanan enneagram insanların kişilik tiplerini incelemekte kullanılan bir öğretidir. Bu öğreti bireyin kendini tanıması ve benliğinin sınırlarını öğrenmesine yardımcı olmaktadır. Tarihsel süreçte psikoloji ve felsefeden etkilenerek günümüze değin gelen enneagram insanların dünyayı algılama, dünyaya bakış açısı ve bunlara tepki verme biçimlerinde farklılıkları kişilik tipleriyle değerlendirmektir. Her kişilik tipinde biri birinden daha üstün olmayan kendine özgü güçlü ve zayıf yönleri olan kişilik tipleri vardır. Her tip kişilik kendi bakış açısıyla olayları değerlendirmekte ve tepki vermektedir (Matise, 2007, s.39). 


\section{Enneagram Kişilik Tipleri}

Özeren (2017) tarafından şekilde görülen 9 enneagram tipi açılanmıştır.

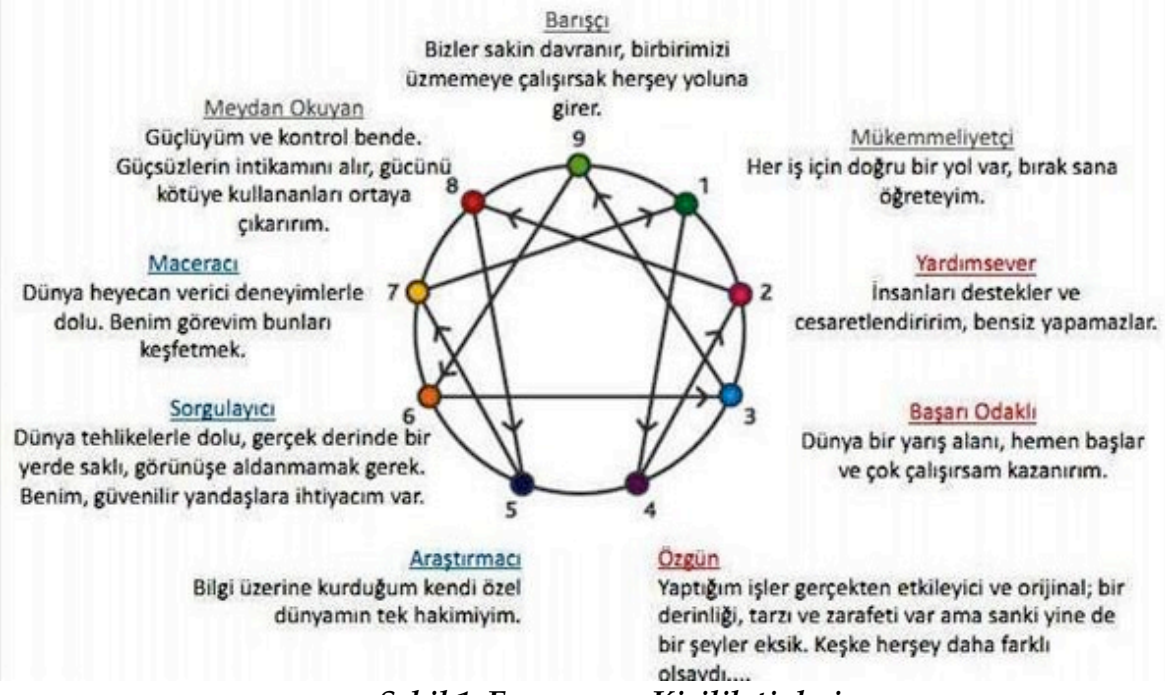

Şekil 1. Enneagram Kişilik tipleri

Tip -1: Mükemmeliyetçi: Enneagram kişilik tipolojisi içerisinde "Tip-Bir" mizacı taşıyan kişiler, hem kendisinin hem de her şeyin "olması gerektiği gibi mükemmel" olmasını isterler. Dürüst, doğru, tutarlı ve erdemli olmaya önem vererek, bunun sağlanmasında özel çaba sarf ederler. Zeki ve titiz yapıda olmaları nedeniyle kendini ve başkalarını sıkça eleştirirler. Belirlenmiş tek doğrunun olduğuna inançlarından dolayı ahlaki bağlamda kendilerini üstün hissederek gayret gösterirler. Bütün detayları titizlikle planladıkları için hata yapmamaya çalışırlar. Bu tipolojideki kişiler üzerinde ince eleyip sık dokuduklarından çalıştıkları projeleri ağır ilerleyebilir. Gereklilik kiplerini (-meli, -malı) çok kullanırlar (Palmer, 2006, s.60).

Tip-2:Yardımsever: Sevgisini ve ilgisini sıklıkla gösterebilen, insanları memnun eden, cömert, sahiplenici yapıdaki kişilerdir. Sağlıklı şekilde empati kuran, merhamet sahibi, başkalarının duygu, düşünce ve hisleri- 
ni paylaşan kişilerdir. Sevgi ve onaya gereksinim duyarlar, bu yüzden muhataplarına karşı verici ve ilgili davranırlar. Bu kişilik tipindekiler muhataplarının beğendiği niteliklerini takdir ve teşvik ederek yakın ve samimi ilişki kurar. Önem verdikleri kişilerin sorunları ile yakından ilgilenirler. Bu yardımsever ve cana yakın tutum ve davranışlarına karşılık, insanlardan da aynı şekilde karşılık beklerler. Çevresinde bulunan insanlardan "özellikle ilgi, şefkat ve onay" isteklerini doğrudan istemek yerine onu öncelikle kendileri vererek diğerlerinin verebileceği karşıllı̆̆ beklerler (Maitri, 2001).

Tip-3:Başarılı: Bu kişilik tipine sahip kişiler uyum sağlayan, hırslı, çok yetenekli ve imaj bilinci taşıyan kişilerdir. Tip- 3'ler, kendilerindeki değeri bir işi ne kadar özenli yaptıklarını, etkin ve prezentabl olduklarını bildikleri için verilen bir göreve tüm benlikleriyle kendilerini adarlar. Düşünce ile eylem adamı olduklarından ulaşılacak bir hedef ya da çözülecek bir sorun olduğunda, vakit kaybetmeksizin en pratik yöntemle hemen eyleme koyulurlar. Bu kişilik tipolojisindeki kişilerde yaşam, birçok etkinlikle doldurulan enerji ve mutluluk kaynağıdır. Bununla beraber kişisel başarılar üzerine odaklanan yapıları gereği, yadsınamaz olarak yakın ilişkileri ve duygusal sorgulara dayanan içsel yaşamlarını ihmal etmeleri olasılık dahilindedir (Palmer, 2006, s.168).

Tip-4:Özgün-Bireysel: Bu kişilik tipolojisine sahip kişiler, kendi his ve düşüncelerini analiz edebilen, kendilerinin farkında olan, duygu ve içsel dürtüleriyle temasta ve benliklerini arayan kişilerdir. Hem kendilerine hem de başkalarına karşı duyarlı, sezgili, düşünceli, merhametli, saygılı ve insanları kırmamaya özen gösteren kişilerdir. Kolay etkilenebilen ve şekillendirilmeye uygun yapıları gereği genelde yalnız kalmayı ve bilinçdışı dürtülerinin bilinç düzeyine çıkmasında vakit geçirmeyi severler. Kendilerini gizlemeden, duygusal anlamda dürüst, samimi bir yap1ya sahiptirler. İç yaşamlarında olduğu kadar, ilişkilerinde de tutkuludurlar. Güzelliklere vurgu yaparak hislerini estetik şekilde ifade ederler. En sağlıklı durumlarında yaratıcı, kişisel ve evrensel olanı muhtemelen ilhamla oluşturdukları bir sanat eseri ile ifade edebilen bir yapıya sahiptir. Kişisel düzeyde, kendilerini yenileyen ve adeta yeniden doğabilen bir özellik kazanırlar (Karabulut, 2007, s.79). 
Tip-5:Araştırmacı: Bu kişilik tipolojisine sahip kişiler olağanüstü bir algılama ve anlayış ile gözlemleme yeteneğine sahiptir. Bu tipte yer alanlar çoğunlukla zihinsel anlamda dikkatli, meraklı ve derinlemesine araştırmaya sahip zekaları vardır. Bu kişileri güçlendiren değerler; bilmek, anlamak, öğrenmek ve bilgeliktir. Bilgelik ile, bulmacanın tüm parçaları$\mathrm{n}$ bir araya getirip resmin bütününü görme kabiliyetleridir. Bir şeyin iç yapısını çabuk kavrama yetisine sahip olmaktan ve bağlantı kurmaktan hoşlanırlar. Bu kişiler gördükleri bilgiyi bir araya getirip sentezleme işlevini iyi yaparlar. Kitapçılarda bile bütün rafları gezip birçok şeyin onların ilgisini çektiğinden her bir şey hakkında bilgi sahibi olmayı isterler (Pesen, 2015, s.48).

Tip-6:Sorgulayıcı: Bu kişilik tipolojisine sahip kişiler diğer insanlar üzerinde güçlü duygusal tepkiler uyandırır. Genelde dost canlısı, çekici, şakacı ve insanları memnun ve minnettar bırakan kişilerdir. Diğer insanlar da bu kişilik yapısına sahip kişilere karşı yakınlık duyarak desteklemek isterler. Bütün kişilik tipleri arasında arkadaşları ve onların inancına en sadık olan tipteki kişiliktir. Bu kişilik tipindeki kişiler aynı zamanda fikirlere, sistemlere ve inançlara da sadık olup bütün fikirlerin sorgulanması, otoriteye karşı konulması fikrine bile sıcaktırlar. Aslında bu kişilik yapısındaki kişiler statükocu değildir, düşünceleri isyankâr, otorite karşıtı hatta devrimci olabilir. Her durumda, inancı için kendileri için savaşacaklarından daha şiddetle savaşıp, toplumu veya ailelerini kendilerini savunacaklarından daha inatla savunurlar (Pesen, 2015, s.49-50).

Tip-7:Maceracı-İstekli: Bu kişilik tipolojisine sahip kişiler dişa karşı çok açık, özgür ruhlu, tepkisel ve deneyimleri konusunda çok istekli olup, nesne ve duyuların dünyasına eğilimleri güçlü olan kişilerdir. Doğal ve ani gelişen olaylara tepki verirler, maceracı ve her tecrübeden mutluluk duyan kişilerdir. Her uyarıcı bu kişilerde ani bir tepkide bulunmaya yol açar ve her şeyi heyecan ve canlılık verici bulurlar. Dünyaya karşı meraklı, genelde hızlı ve kıvrak bir zekâya sahiptirler. Üstün yetenekleri ve etkileyici becerileri sayesinde pek çok farklı işi iyi aynı anda yapabilen, başarılı ve çok yönlü kişilerdir. Bu kişiler pratik, üretken ve aksiyon adamı olmaları hasebiyle aktif zihinlerini hayatın birçok alanında araştırmaya yönlendirir. Çok yönlü olmaları sebebiyle tecrübelerini derinden 
özümserler, iyilik karşısında kadirşinas olurlar. Neşeli ve mutlu olduklarından ruhani gerçeklerin ipuçlarını aramayı ve yaşamın sınırsız haz duygusunu yakalamaya çalışırlar (Karabulut, 2007, s.109-110).

Tip-8:Reis-Meydan Okuyan: Bu kişilik tipolojisine sahip kişiler kendinden emin, iddialı ve güçlü kişiler olup gereksinim duydukları ve istediklerini almada kendilerini savunma ve karşı direnmeyi öğrenmişlerdir. Aksiyom adamı olup istekli, özgüven dolu içsel enerjileri vardır. Bu enerjileri ile, güç odakll, kendine güveni tam, hükümran olan, kontrol etmeye eğilimli kişilerdir. Herhangi birinden emir almaktansa bir yerden sorumlu olmayı, patron olmayı ve emirler vermeyi isterler. Etkin ve baskın kişilikleri nedeniyle fiziksel veya başka şekillerde varlıklarını hissettirirler. Haksızlığa tahammül edemezler, kendilerine veya bulundukları yerdeki birine haksızlık yapıldığını düşünürlerse, duruma el atarak gerekirse şiddete başvurup öznel adaletlerini tesis etmek isterler. Karşısındaki insana hak ettiklerini düşündüğü biçimde davranırlar. Bütün bunlar aslında bu kişilerin kendini ve alanını koruma, adaleti sağlama ve güçlü olduğunu hissetme ve hissettirme çalışmasıdır (Maitri, 2001).

Tip-9:Uzlaşmacı: Bu kişilik tipolojisine sahip kişiler fiziksel ihtiyaçlarını, hayatlarını, vazgeçilmez düşündükleri iç huzur ve dinginlikleri muhafazasın etmekte kurgularlar. Bu duruma zarar verebilecek her çeşit unsurdan, çatışma ve uyumsuzluk durumundan uzak kalmayı veya bu türden durumları ötelemeye eğilimlidir. Nadiren iddialı davranış sergilerler. Başkaların tarafından "rahatsız edici", "saldırgan" bulduğu veya karşı çıkıp eleştirdiği, dikkate almadığı şeyleri söylemek ya da yapmakta zorlanırlar. Bu sebepten dolayı çatışmaktan kaçınıp olumsuz duyguları ve düşünceleri nadiren ifade ederler. Genellikle olumluya odaklanıp iyi bir arabulucu olurlar. Olayları herkesin bakış açısıyla görür, ancak kendi bakış açlarını belirleme, tanımlama ve ifadesinde zorlanırlar. Kendileri açısından önemli olan şeyleri hesaplamada ve buna odaklanmada zorlanırlar. Bu durumda içsel yaşamları, bireysel tercihleri ve öncelikleri ihmal etmeye, duyguları ve düşüncelerine dikkat etmemeye, yaşamlarında gereksinim duyacakları şeyleri önemsememeye götürür (Maitri, 2001). 


\section{Müşteri Bağlılı̆̆}

Tarihsel gelişim sürecinde pazarlama tüketici istek ve beklentilerinin gelişip değişmesine sebep olmuştur. Bu süreçte işletmeler pazarlama stratejilerini tüketici istek ve beklentileri ile örtüştürmeye çalışmıştır. Günümüzde pazarlama üretilen mal ve hizmetlerin satılmasından ziyade tüketici istek ve beklentilerinin doygunluğuna yönelmiştir. Bu bağlamda artık müşteri memnuniyeti ve müşteri bağl1lı̆̆ 1 önem kazanmaya başlamıştır. İşletmelerin hedefi optimal kar elde etmekten çıkmış tüketici istek ve beklentilerinin anlaşılmasının önemi fazlasıyla fark edilir olmuştur (Özgüven, 2010, s.58). Müşteri bağlılığının rekabet etmedeki bu önemi nedeniyle, işletmeler müşteri bağlılığı kazanmak için fırsatlar aramaya yönelterek mevcut müşterilerle de daha çok ilgilenmeye zorlamıştır. Bunun için işletmeler, mevcuttaki müşterileri hem işletmeye hem de işletmelerin sunduğu mal/hizmetlere, markaya bağlılık duyan müşteri haline getirmeyle ilgili pazarlama stratejilerini hazırlamaya yöneltmiştir (Barutçu, 2007). Bunun sayesinde işletmeler, yeni kazanacakları müşteriler için yapılacak pazarlama masraflarının yerine, sadık müşterilerdeki pozitif düşünceler ve tavsiyeler yolu ile yeni müşteriler kazanma ve mevcut müşterilerin elde tutulmasını ümit etmektedirler (Bowen ve Shoemaker, 1998).

Müşteri bağlılığı, müşterinin tercih etme hakkı olduğu zamanda, aynı ürün/markayı satın almayı istemesi ya da gereksinim duyduğu ihtiyaçların çözümünde her zamanki sıklık ile aynı işletme/mağazayı seçme eğilimi, arzusu ve eylemleri olarak tanımlanabilir (Odabaşı, 2000). Müşteri bağlılı̆̆ı konusunda yapılan araştırmaların çoğunda tüketicinin somut ürünlere dönük bağlılık göstermeleri temel alınmış ve genelde tanımlama ise marka bağllı̆̆ı üzerinden olmuştur. 1960- 1970'li yıllarda yapılan araştırmalar, marka bağlılığına yönelip marka bağlılığı tanım ve ölçümlenmesi üzerine odaklanmıştır. Müşteri bağl1lığı araştırmalarında somut ürünlerle ilgili marka bağlılı̆̆ 1 üzerinde yapılan çalışmalar mağazaya bağlılık, satıcıya bağlılık ve hizmete bağlılık olacak biçimde genişleme göstermiştir (Caruana, 2002, s.811).

İşletmeler açısından müşteriyi elde tutmak günümüz acımasız rekabet ortamında önemli hale gelmiştir. Rekabetin gittikçe ivme kazanmasıyla işletmeler müşterilerle daha çok ilgilenmek ve müşteri bağl1lı̆̆1 
oluşturmak zorunda kalmışlardır. Bu yönüyle işletmelerin müşterilerini elde tutmak ve müşteri bağlılığını kazanmanın yollarını aramaktadırlar (Özgüven, 2010:64). İşletmeler yoğun rekabette sürdürülebilir olmalarını müşteri bağlılığını temin etmek suretiyle sağlayıp pazar paylarını korumaktadır. Bunu yaparken mevcut müşterilerin deneyimlerinden hareketle yeni müşteriler kazanma yoluna gitmeleri zorunluluk haline gelmiştir (Selvi ve Ercan, 2006, s.181).

İşletmeye bağlı müşteriler sayesinde, finansal ve pazarlama uygulamaları açısından zayıf olunan zamanda bile müşteriler işletmenin yanında olurlar. Bağlllığ1 yüksek müşteriler çevrelerine işletmeyle ilgili olumlu tavsiyeler söyleyerek işletmenin reklam ve tanınırlılığını sağlarlar. Ayrıca bu müşteriler, işletmeleri için gönülden harcama yaparak olumsuz koşulların olduğu zamanlarda bile işletmelerini terk etmezler (Özgüven, 2010, s.66).

\section{Veri, Yöntem ve Hipotezler}

Bu araştırmanın amacı Enneagram'ın Müşteri Bağlılığı üzerindeki etkileşiminin belirlenmesidir. Bu amaçla Kütahya ilindeki serbest muhasebeci ve mali müşavirlerden muhasebe hizmeti alan 201 gönüllü mükellefe ulaşılmıştır. Araştırma için 2 ölçek ile demografik özelliklerden oluşan veriler kullanılmıştır. Enneagram Kişilik ölçeği 27 ifade, Müşteri Bağlılığ ölçeği 15 ifadeden oluşmaktadır. Toplam 42 ifade Likert tipinde (1.Beni Hiç Anlatmıyor,- 4.Tamamı Beni Anlatıyor; 1.Hiç Katılmıyorum,-4.Tamamen Katılıyorum) ve 6 adet demografik özellik içeren ifadelerden oluşan anket 201 mükellefe uygulanmıştır. Araştırmada kullanılan ilk ölçek Enneagram Kişilik ölçeği; Şubaş ve Çetin (2017) geliştirdiği ölçektir. İkinci ölçek; Müşteri Bağlılığı Ölçeği Bektaş ve Aydın (2018) çalışmasında kullandığı ölçektir. Araştırma verilerinin analizi için SPSS (20.0) programı kullanılmıştır. Araştırmanın kavramsal modeli Şekil 1.'de sunulmuştur. 
Enneagram (EN)

Müşteri Bağlılığı (MB)

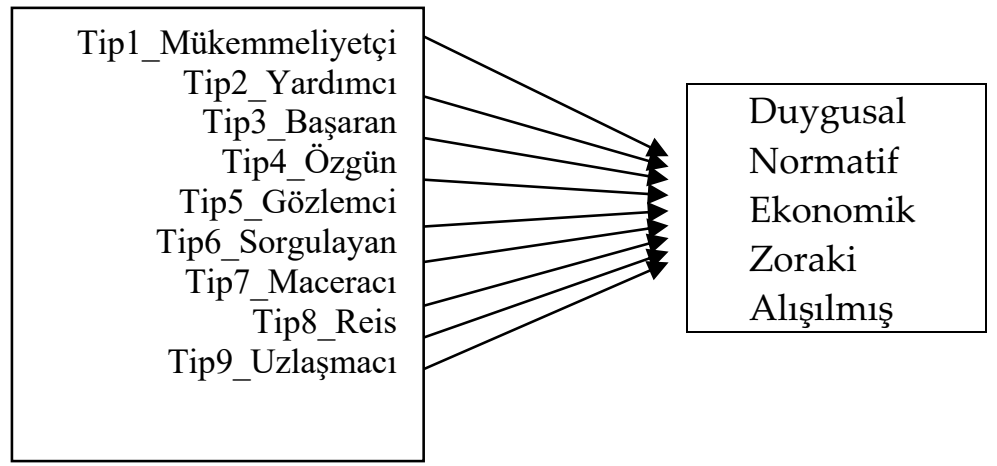

Şekil 1. Araştırmanın Modeli

Araştırmaya ait hipotezler şunlardır;

- H1: Enneagram Müşteri Bağlılı̆g üzerinde anlamlı etkiye sahiptir

- $\quad \mathrm{H}_{2}$ : Enneagram alt faktörü (Tip1_Mükemmeliyetçi) Müşteri Bağl1lığı üzerinde anlamlı etkiye sahiptir

- H3: Enneagram alt faktörü (Tip2_Yardımc1) Müşteri Bağlılığ1 üzerinde anlamlı etkiye sahiptir

- H4: Enneagram alt faktörü (Tip3_Başaran) Müşteri Bağl1lığı üzerinde anlamlı etkiye sahiptir

- H5: Enneagram alt faktörü (Tip4_Özgün) Müssteri Bağl1lı̆ğ üzerinde anlamlı etkiye sahiptir

- H6: Enneagram alt faktörü (Tip5_Gözlemci) Müşteri Bağl1lığı üzerinde anlamlı etkiye sahiptir

- H7: Enneagram alt faktörü (Tip6_Sorgulayan) Müşteri Bağlllığ1 üzerinde anlamlı etkiye sahiptir

- H8: Enneagram alt faktörü (Tip7_Macerac1) Müşteri Bağlılığı üzerinde anlamlı etkiye sahiptir

- H9: Enneagram alt faktörü (Tip8_Reis) Müşteri Bağlılığı üzerinde anlamlı etkiye sahiptir

- H10: Enneagram alt faktörü (Tip9_Uzlaşmacı) Müşteri Bağl1lığ1 üzerinde anlamlı etkiye sahiptir 


\section{Bulgular}

Bu kısımda araştırma kapsamındaki Kütahya ilindeki 201 mükellef ile oluşturulan verilerle demografik özellikleri, kullanılan ölçeklerin örneklem yeterlilikleri, güvenilirlik analizleri, frekans dağılımları, fark testleri, korelasyon, regresyon analizleri vb. ile yorumlanması yer almaktadır.

Tablo 1.Demografik Özellikler

\begin{tabular}{|c|c|c|c|c|c|}
\hline Cinsiyet & Frekans & $\%$ & Medeni Durum & Frekans & $\%$ \\
\hline Kadin & 24 & 11,9 & Evli & 180 & 89,6 \\
\hline Erkek & 177 & 88,1 & Bekâr & 21 & 10,4 \\
\hline Yaş & Frekans & $\%$ & Meslek & Frekans & $\%$ \\
\hline $18-28$ & 14 & 7,0 & Zanaatkar & 22 & 10,9 \\
\hline $29-38$ & 64 & 31,8 & Küçük Esnaf & 13 & 6,5 \\
\hline $39-46$ & 75 & 37,3 & Yük.Teknoloji Meslekleri & 8 & 4,0 \\
\hline $47-53$ & 38 & 18,9 & İnşaat-Müteahhitlik & 26 & 12,9 \\
\hline 54 ve üzeri & 10 & 5,0 & Gida-Market-Bakkal & 26 & 12,9 \\
\hline Eğitim & Frekans & $\%$ & Sarraf & 4 & 2,0 \\
\hline İlkögretim & 22 & 10,9 & Fırın İşletmesi & 4 & 2,0 \\
\hline Lise & 129 & 64,2 & Otobüs-Taksi-Nakliyat & 25 & 12,4 \\
\hline Ön Lisans & 7 & 3,5 & Eczacı & 4 & 2,0 \\
\hline Lisans & 41 & 20,4 & Kirtasiye-Matbaa & 4 & 2,0 \\
\hline \multirow[t]{3}{*}{ Lisansüstü } & 2 & 1,0 & Emlak-Galeri & 4 & 2,0 \\
\hline & & & Avukat & 8 & 4,0 \\
\hline & & & Terzi & 7 & 3,5 \\
\hline Gelir TL. & Frekans & $\%$ & Kuaför & 5 & 2,5 \\
\hline $0-2020$ & 13 & 6,5 & Araç Tamir-Bakım & 14 & 7,0 \\
\hline $2021-4000$ & 64 & 31,8 & Çay Ocağ & 5 & 2,5 \\
\hline $4001-6000$ & 63 & 31,3 & Hizmet İşletmesi & 10 & 5,0 \\
\hline $6001-8000$ & 44 & 21,9 & Hayvan Sağlığ1 & 6 & 3,0 \\
\hline 8001 üstü & 17 & 8,5 & Diğer & 6 & 3,0 \\
\hline
\end{tabular}

Tabloya göre araştırmaya katılanların çoğunluğu erkek $(\% 88,1)$, evli $(\% 89,6)$, yaş aralığı 39-46 (\%37,3), eğitim düzeyleri lise (\%64,2), aylık gelirleri 2021-4000 TL. $(\% 31,8)$, meslekleri inşaat-müteahhitlik $(\% 12,9)$ olduğu görülmektedir. 


\section{Ölçeklerin Geçerlilik ve Güvenilirlik Analizi}

Araştırma verilerinin faktör analizine uygunluğunun testi için KaiserMeyer-Olkin (KMO) örneklem yeterliliği testi ve Bartlett Küresellik testi yapılmıştır. KMO örneklem yeterliliği testinde uygun olan alt sınır değeri 0,50'dir. Bu değerin 0,60-0,80 arası yeterli iken 0,80 - 0,90 arasında olması çok iyi olarak değerlendirilmektedir. Normal dağılımın göstergesi olarak Eğiklik/Basıklık değerleri -3 ile +3 arasında olmalıdır. (Kalaycı, 2010:322). Ortak varyansın açıklanmasında 200 üstü örneklemlerde 0,50'den büyük olması beklenmelidir (Field 2007). Faktörlerin korelasyona bağlı iç tutarlıkları için Cronbach's Alpha katsayısının 0,80'den yüksek olması iyi olarak değerlendirilebilir (Büyüköztürk, 2007).

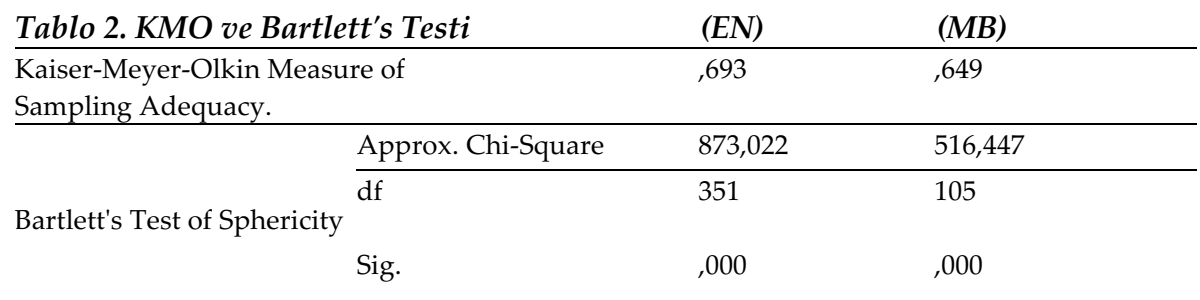

Tabloya göre oluşan Enneagram (EN) ve Müşteri Bağlllı̆̆1 (MB) ölçeği KMO değeri 0,693 ve 0,649 ile yeterli olduğu tespit edilmiştir.

Tablo 3. Güvenilirlik analizi.

\begin{tabular}{llll}
\hline $\mathbf{( E N )}$ & $\mathbf{( M B )}$ & \\
\hline Cronbach's Alpha & $\mathrm{n}$ & Cronbach's Alpha & $\mathrm{n}$ \\
\hline, 759 & 27 &, 645 & 15 \\
\hline
\end{tabular}

Tabloya göre oluşan Enneagram (EN) ve Müşteri Bağlılı̆̆ $(\mathrm{MB})$ ölçeği Cronbach's Alpha Değeri 0,759 ve 0,645 ile yeterli olduğu tespit edilmiştir.

\section{Demografik Özellikler ile değişkenlere ait T-Testleri ve Anova Testleri}

Demografik özellikler ile Enneagram (EN) ve Müşteri Bağlılığı (MB) arasındaki ilişkiler t-testi ve Anova ile analiz edilmiştir. T-Testi iki örneklem 
arasındaki ortalamanın önemli seviyede farklılık olup/olmadığının ayırt edilmesinde kullanılmaktadır (Kalaycı, 2010, s.74). Tek yönlü varyans (ANOVA) yapmanın gayesi ise ikiden fazla örneklem grubu arasında bulunan ortalamaların farklı olup/olmadığının ayırt edilmesinde kullanilmaktadır (Kalaycı, 2010, s.131).

Tablo 4. Gelir ile Enneagram ve Müşteri Bağlılı̆̆ı arasında ANOVA

\begin{tabular}{|c|c|c|c|c|c|c|}
\hline & & Kare. Top. & Ser. Derec. & Kare. Ort. & $\mathbf{F}$ & $\mathbf{P}$ \\
\hline \multirow[t]{3}{*}{ EN } & Gruplararası & 1,349 & 4 & ,337 & 7,736 & , 000 \\
\hline & Grupiçi & 8,543 & 196 & ,044 & & \\
\hline & Top. & 9,892 & 200 & & & \\
\hline \multirow[t]{3}{*}{ MB } & Gruplararası & 1,483 & 4 & 371 & 6,881 & ,000 \\
\hline & Grupiçi & 10,562 & 196 & 054 & & \\
\hline & Top. & 12,045 & 200 & & & \\
\hline
\end{tabular}

Tabloya göre yaşın $p<0,05$ anlamlılık değeri üzerinden 6001-8001 TL. gelir sahipleri ile 0-2020 TL, 2021-4000 TL. arasında Enneagram ve Müşteri Bağlılığı arasında pozitif yönde anlamlı bir farklılık vardır. Bu durum mükelleflerin gelir düzeyi yükseldikçe müşteri bağlılıklarının artışıyla açıklanabilir.

\section{Değişkenler arası Korelasyon Analizleri}

İki yahut daha fazla değişkenin arasında bulunan ilişkinin büyüklük, düzey ve yönünün tespitinde kullanılan istatistiki metoda korelasyon denir. Nedensellik ile korelasyon birbirine yakın kavramlar gibi görülse de farklı kavramlar olup araştırmacıya nedenselliğin sebebini bulmakta önbilgi verir (Gürbüz ve Şahin, 2014). Korelasyon analizinde ilişkinin varlığı korelasyon katsayısıyla bulunabilir. " $r$ " ile gösterilen korelasyon katsayısı -1 ile +1 arasında değerler almaktadır (Nakip, 2006:342-343). Açımlayıcı ve Keşfedici Faktör analizi ile belirlenen değişkenler arasındaki ilişkilerin bulunmasında "Pearson Korelasyon Analizi" kullanılmaktadır. Bu analizde $\mathrm{r}=$ "0,80-1,00 Çok Yüksek" ,"0,60-0,80 Yüksek", "0,40-0,60 Orta”, “0,20-0,40 Zayıf”, "0,00-0,20 Çok Zayıf” ilişki olduğu değerlendirilmektedir (Akgül ve Çevik, 2005:359). Enneagram ile Müşteri Bağlılığı arasında bulunan ilişkinin tespitinde Pearson Korelasyon testi yapılmıştır. 
Tablo 5. Enneagram ile Müşteri Bağlılı̆̆ı arasında Korelasyon analizi

\begin{tabular}{llll}
\hline Değişkenler & & EN & MB \\
\hline EN & Pearson C. & 1 &, $603^{* *}$ \\
& Sig. (2-) & &, 000 \\
& N & 201 & 201 \\
\hline MB & Pearson C. &, $603^{* *}$ & 1 \\
& Sig. (2-) &, 000 & \\
& N & 201 & 201 \\
\hline
\end{tabular}

Tabloda görüldüğü üzere Enneagram ile Müşteri Bağlılığı arasında $(\mathrm{r}=0,603)$ kuvvetinde $\mathrm{p}<0,005$ anlamlılık düzeyinde pozitif yönlü yüksek düzeyde bir ilişki vardır.

\section{Değişkenler arası Regresyon Analizi}

Regresyon analizinin yapılmasının gayesi; değişkenler arasındaki etkinin test edilmesi, iki değişkenden birinin değişiminin diğerindeki değişimi açıklanmasında kullanılan istatistiksel yöntemdir. Bu yöntem genellikle değişkenler arasındaki neden-sonuç ilişkisinin test edilebilmesinde kullanılmaktadır. Birden çok bağımsız değişken ile geçerli ve açıklayıcı modeller üretilebildiğinden dolayı sıklıkla kullanılan istatistiksel yöntemlerden biridir (Güriş ve Çağlayan, 2005, s.199). Regresyon analizinde R:bağımlı değişken ile bağımsız değişkenler arasında olan korelasyonu, $\mathrm{R}^{2}$ : bağımlı değişkendeki değişimin bağımsız değişken tarafından ne kadarına kadar açıkladığı, F: yapılan regresyon analizinin anlamlı olup/olmadığını ( $p<0,05$ den küçük olması), $\beta$ : bağımsız değişkenin etkisinin sabit tutularak bağımlı değişken üzerindeki etkisinin testinde kullanılmaktadır (Kalaycı, 2010, s.259-269). Araştırmanın bu kısmında Enneagram kişilik tipleri ile Müşteri Bağlılığı arasındaki regresyon analizleri sunulmuştur. 
Tablo 6. Regresyon analizi

\begin{tabular}{|c|c|c|c|c|c|}
\hline \multirow[t]{2}{*}{ Model EN ile MB } & $\mathbf{R}$ & $\mathbf{R}^{2}$ & Tah. S.H. & $\mathbf{F}$ & $\mathbf{P}$ \\
\hline & 0,603 & 0,364 & 0,19627 & 113,687 & ,000 \\
\hline \multirow{2}{*}{ Sabit } & $\beta$ & S.H. & Beta & $\mathrm{t}$ & $\mathbf{P}$ \\
\hline & 1,090 & 0,195 & & 5,598 & 0,000 \\
\hline EN & 665 & 0,062 & 0,603 & 10,662 & 0,000 \\
\hline \multicolumn{6}{|l|}{$M B=1,090+0,665^{*}(E N)$} \\
\hline \multirow[t]{2}{*}{ Model EN Tip-1 ile MB } & $\mathbf{R}$ & $\mathbf{R}^{2}$ & Tah. S.H. & $\mathbf{F}$ & $\mathbf{P}$ \\
\hline & 0,295 & 0,087 & 0,23509 & 18,943 & 0,000 \\
\hline \multirow{2}{*}{ Sabit } & $\beta$ & S.H. & Beta & $\mathbf{t}$ & $\mathbf{P}$ \\
\hline & 2,554 & 0,140 & & 18,234 & 0,000 \\
\hline EN Tip-1 & 198 & 0,045 & 0,295 & 4,352 & 0,000 \\
\hline \multicolumn{6}{|l|}{$M B=2,554+0,198^{*}($ EN Tip -1$)$} \\
\hline \multirow[t]{2}{*}{ Model EN Tip-2 ile MB } & $\mathbf{R}$ & $\mathbf{R}^{2}$ & Tah. S.H. & $\mathbf{F}$ & $\mathbf{P}$ \\
\hline & 0,290 & 0,084 & 0,23547 & 18,247 & 0,000 \\
\hline \multirow{2}{*}{ Sabit } & $\beta$ & S.H. & Beta & $\mathbf{t}$ & $\mathbf{P}$ \\
\hline & 2,486 & 0,159 & & 15,672 & 0,000 \\
\hline EN Tip-2 & ,221 & 0,052 & 0,290 & 4,272 & 0,000 \\
\hline \multicolumn{6}{|l|}{$M B=2,486+0,221^{*}($ EN Tip -2$)$} \\
\hline \multirow[t]{2}{*}{ Model EN Tip-3 ile MB } & $\mathbf{R}$ & $\mathbf{R}^{2}$ & Tah. S.H. & $\mathbf{F}$ & $\mathbf{P}$ \\
\hline & 0,355 & 0,126 & 0,22997 & 28,766 & 0,000 \\
\hline \multirow{2}{*}{ Sabit } & $\beta$ & S.H. & Beta & $\mathrm{t}$ & $\mathbf{P}$ \\
\hline & 2,383 & 0,146 & & 16,346 & ,000 \\
\hline EN Tip-3 & 246 & 0,046 & 0,355 & 5,363 & 0,000 \\
\hline \multicolumn{6}{|l|}{$M B=2,383+0,246^{*}(E N$ Tip -3$)$} \\
\hline \multirow[t]{2}{*}{ Model EN Tip-4 ile MB } & $\mathbf{R}$ & $\mathbf{R}^{2}$ & Tahmini S.H. & $\mathbf{F}$ & $\mathbf{P}$ \\
\hline & 0,462 & 0,214 & 0,21815 & 54,101 & 0,000 \\
\hline \multirow{2}{*}{ Sabit } & $\beta$ & S.H. & Beta & $\mathrm{t}$ & $\mathbf{P}$ \\
\hline & 2,249 & 0,125 & & 18,036 & 0,000 \\
\hline EN Tip-4 & ,293 & 0,040 & 0,462 & 7,355 & 0,000 \\
\hline \multicolumn{6}{|l|}{$M B=2,249+0,293^{*}($ EN Tip -4$)$} \\
\hline \multirow[t]{2}{*}{ Model EN Tip-5 ile MB } & $\mathbf{R}$ & $\mathbf{R}^{2}$ & Tah. S.H. & $\mathbf{F}$ & $\mathbf{P}$ \\
\hline & 0,384 & 0,147 & 0,22997 & 34,324 & 0,000 \\
\hline \multirow{2}{*}{ Sabit } & $\beta$ & S.H. & Beta & $\mathrm{t}$ & $\mathbf{P}$ \\
\hline & 2,448 & 0,123 & & 19,975 & ,000 \\
\hline EN Tip-5 & 229 & 0,039 & 0,384 & 5,859 & 0,000 \\
\hline \multicolumn{6}{|l|}{$M B=2,448+0,229 *(E N$ Tip -5$)$} \\
\hline \multirow[t]{2}{*}{ Model EN Tip-6 ile MB } & $\mathbf{R}$ & $\mathbf{R}^{2}$ & Tah. S.H. & $\mathbf{F}$ & $\mathbf{P}$ \\
\hline & 0,344 & 0,118 & 0,23102 & 26,696 & 0,000 \\
\hline \multirow{2}{*}{ Sabit } & $\beta$ & S.H. & Beta & $t$ & $\mathbf{P}$ \\
\hline & 2,510 & 0,127 & & 19,789 & 0,000 \\
\hline EN Tip-6 & 207 & 0,040 & 0,344 & 5,167 & 0,000 \\
\hline \multicolumn{6}{|l|}{$M B=2,249+0,207^{*}($ EN Tip-6) } \\
\hline \multirow[t]{2}{*}{ Model EN Tip-7 ile MB } & $\mathbf{R}$ & $\mathbf{R}^{2}$ & Tah. S.H. & $\mathbf{F}$ & $\mathbf{P}$ \\
\hline & 0,401 & 0,161 & 0,22536 & 38,160 & 0,000 \\
\hline \multirow{2}{*}{ Sabit } & $\beta$ & S.H. & Beta & $\mathbf{t}$ & $\mathbf{P}$ \\
\hline & 2,322 & 0,137 & & 17,007 & 0,000 \\
\hline
\end{tabular}




\begin{tabular}{|c|c|c|c|c|c|}
\hline EN Tip-7 & ,269 & 0,044 & 0,401 & 6,177 & 0,000 \\
\hline \multicolumn{6}{|c|}{$M B=2,322+0,269^{*}($ EN Tip -7$)$} \\
\hline \multirow[t]{2}{*}{ Model EN Tip-8 ile MB } & $\mathbf{R}$ & $\mathbf{R}^{2}$ & Tah. S.H. & $\mathbf{F}$ & $\mathbf{P}$ \\
\hline & 0,334 & 0,111 & 0,23193 & 24,923 & 0,000 \\
\hline \multirow{2}{*}{ Sabit } & $\beta$ & S.H. & Beta & $\mathrm{t}$ & $\mathbf{P}$ \\
\hline & 2,469 & 0,139 & & 17,711 & 0,000 \\
\hline EN Tip-8 & 219 & 0,044 & 0,334 & 4,992 & 0,000 \\
\hline \multicolumn{6}{|l|}{$M B=2469+0,219 *($ EN Tip -8$)$} \\
\hline \multirow[t]{2}{*}{ Model EN Tip-9 ile MB } & $\mathbf{R}$ & $\mathbf{R}^{2}$ & Tah. S.H. & $\mathbf{F}$ & $\mathbf{P}$ \\
\hline & 0,336 & 0,113 & 0,23175 & 25,271 & 0,000 \\
\hline \multirow{2}{*}{ Sabit } & $\beta$ & S.H. & Beta & $t$ & $\mathbf{P}$ \\
\hline & 2,506 & 0,131 & & 19,112 & 0,000 \\
\hline EN Tip-9 & ,211 & 0,042 & 0,336 & 5,027 & 0,000 \\
\hline \multicolumn{6}{|c|}{$M B=2,506+0,211^{*}($ EN Tip-9) } \\
\hline
\end{tabular}

Tabloya göre Enneagram Tip-9 ile Müşteri Bağlılığı değişkeni arasındaki ilişkinin sınanması için yapılan regresyon analizinde $(F=25,271$; $\mathrm{p}<0,05)$ istatistiki olarak anlamlı bir ilişki belirlenmiştir. Belirlilik katsayıs1 $R^{2}=0,113$ olarak bulunmuş olup, Müşteri Bağlılığındaki değişimin \%11,3'ü Enneagram Tip-9 tarafından açıklandığı söylenebilir.

Tabloya göre Enneagram Tip-8 ile Müşteri Bağlllığı değişkeni arasındaki ilişkinin sınanması için yapılan regresyon analizinde $(\mathrm{F}=24,923$; $\mathrm{p}<0,05)$ istatistiki olarak anlamlı bir ilişki belirlenmiştir. Belirlilik katsayıs1 $R^{2}=0,111$ olarak bulunmuş olup, Müşteri Bağlllığındaki değişimin \%11,1'i Enneagram Tip-8 tarafından açıklandığı söylenebilir.

Tabloya göre Enneagram Tip-7 ile Müşteri Bağlllığı değişkeni arasındaki ilişkinin sınanması için yapılan regresyon analizinde $(\mathrm{F}=38,160$; $\mathrm{p}<0,05)$ istatistiki olarak anlamlı bir ilişki belirlenmiştir. Belirlilik katsay1s1 $\mathrm{R}^{2}=0,161$ olarak bulunmuş olup, Müşteri Bağlılığındaki değişimin \%16,1'i Enneagram Tip-7 tarafından açıklandığı söylenebilir.

Tabloya göre Enneagram Tip-6 ile Müşteri Bağlılığı değişkeni arasındaki ilişkinin sınanması için yapılan regresyon analizinde $(\mathrm{F}=26,696$; $\mathrm{p}<0,05)$ istatistiki olarak anlamlı bir ilişki belirlenmiştir. Belirlilik katsayıs1 $\mathrm{R}^{2}=0,118$ olarak bulunmuş olup, Müşteri Bağlılığındaki değişimin \%11,8'i Enneagram Tip-6 tarafından açılandığı söylenebilir.

Tabloya göre Enneagram Tip-5 ile Müşteri Bağlllı̆̆ değişkeni arasındaki ilişkinin sınanması için yapılan regresyon analizinde $(\mathrm{F}=34,324$; $\mathrm{p}<0,05)$ istatistiki olarak anlamlı bir ilişki belirlenmiştir. Belirlilik katsayı- 
S1 $\mathrm{R}^{2}=0,147$ olarak bulunmuş olup, Müşteri Bağlllığındaki değişimin \%14,7'si Enneagram Tip-5 tarafından açıklandığı söylenebilir.

Tabloya göre Enneagram Tip-4 ile Müşteri Bağlllığı değişkeni arasındaki ilişkinin sınanması için yapılan regresyon analizinde $(F=54,101$; $\mathrm{p}<0,05)$ istatistiki olarak anlamlı bir ilişki belirlenmiştir. Belirlilik katsayıs1 $\mathrm{R}^{2}=0,214$ olarak bulunmuş olup, Müşteri Bağlılığındaki değişimin \%21,4'ü Enneagram Tip-4 tarafından açıklandığı söylenebilir.

Tabloya göre Enneagram Tip-3 ile Müşteri Bağlllı̆̆ değişkeni arasındaki ilişkinin sınanması için yapılan regresyon analizinde $(\mathrm{F}=28,766$; $\mathrm{p}<0,05)$ istatistiki olarak anlamlı bir ilişki belirlenmiştir. Belirlilik katsay1s1 $\mathrm{R}^{2}=0,126$ olarak bulunmuş olup, Müşteri Bağlılı̆̆ındaki değişimin \%12,6's Enneagram Tip-3 tarafından açıklandığı söylenebilir.

Tabloya göre Enneagram Tip-2 ile Müşteri Bağlllığı değişkeni arasındaki ilişkinin sınanması için yapılan regresyon analizinde $(\mathrm{F}=18,247$; $\mathrm{p}<0,05)$ istatistiki olarak anlamlı bir ilişki belirlenmiştir. Belirlilik katsayıs1 $\mathrm{R}^{2}=0,084$ olarak bulunmuş olup, Müşteri Bağlılığındaki değişimin \%8,4'ü Enneagram Tip-2 tarafından açıklandığı söylenebilir.

Tabloya göre Enneagram Tip-1 ile Müşteri Bağlllı̆̆ değişkeni arasındaki ilişkinin sınanması için yapılan regresyon analizinde $(\mathrm{F}=18,943$; $\mathrm{p}<0,05)$ istatistiki olarak anlamlı bir ilişki belirlenmiştir. Belirlilik katsay1s1 $\mathrm{R}^{2}=0,087$ olarak bulunmuş olup, Müşteri Bağlılı̆̆ındaki değişimin \%8,7'si Enneagram Tip-1 tarafından açıklandığı söylenebilir.

Tabloya göre Enneagram ile Müşteri Bağlılığ1 değişkeni arasındaki ilişkinin sınanması için yapılan regresyon analizinde $(\mathrm{F}=11,687 ; \mathrm{p}<0,05)$ istatistiki olarak anlamlı bir ilişki belirlenmiştir. Belirlilik katsayısı $R^{2}=$ 0,364 olarak bulunmuş olup, Müşteri Bağlllığındaki değişimin \%36,4'ü Enneagram tarafından açılandığı söylenebilir. 
Tablo 7. Hipotezlerin test edilmesi

\begin{tabular}{|c|c|c|}
\hline Hipotez & $\mathbf{P}$ & Sonuç \\
\hline $\mathrm{H}_{1}$ : Enneagram Müssteri Bağl1lığı üzerinde anlamlı etkiye sahiptir & 0,000 & Kabul \\
\hline $\begin{array}{l}\mathrm{H}_{2} \text { : Enneagram alt faktörü (Tip1_Mükemmeliyetçi) Müşteri Bağl1llğı üzerin- } \\
\text { de anlamlı etkiye sahiptir }\end{array}$ & 0,000 & Kabul \\
\hline $\begin{array}{l}\text { H3: Enneagram alt faktörü (Tip2_Yardımcı) Müşteri Bağllı̆ı̆ı üzerinde anlam- } \\
\text { lı etkiye sahiptir }\end{array}$ & 0,000 & Kabul \\
\hline $\begin{array}{l}\text { H4: Enneagram alt faktörü (Tip3_Başaran) Müşteri Bağl1lı̆̆ }{ }_{1} \text { üzerinde anlamlı } \\
\text { etkiye sahiptir }\end{array}$ & 0,000 & Kabul \\
\hline $\begin{array}{l}\text { H5: Enneagram alt faktörü (Tip4_Özgün) Müşteri Bağlllığı üzerinde anlamlı } \\
\text { etkiye sahiptir }\end{array}$ & 0,000 & Kabul \\
\hline $\begin{array}{l}\text { H6: Enneagram alt faktörü (Tip5_Gözlemci) Müşteri Bağlllı̆̆ı üzerinde an- } \\
\text { lamlı etkiye sahiptir }\end{array}$ & 0,000 & Kabul \\
\hline $\begin{array}{l}\text { H7: Enneagram alt faktörü (Tip6_Sorgulayan) Müşteri Bağlllığı üzerinde } \\
\text { anlamlı etkiye sahiptir }\end{array}$ & 0,000 & Kabul \\
\hline $\begin{array}{l}\text { H8: Enneagram alt faktörü (Tip7_Maceracı) Müşteri Bağlllı̆̆g üzerinde anlam- } \\
\text { lı etkiye sahiptir }\end{array}$ & 0,000 & Kabul \\
\hline $\begin{array}{l}\text { H9: Enneagram alt faktörü (Tip8_Reis) Müşteri Bağlılığı üzerinde anlamlı } \\
\text { etkiye sahiptir }\end{array}$ & 0,000 & Kabul \\
\hline $\begin{array}{l}\text { H10: Enneagram alt faktörü (Tip9_Uzlaşmacı) Müşteri Bağlllı̆̆ı üzerinde } \\
\text { anlamlı etkiye sahiptir }\end{array}$ & 0,000 & Kabul \\
\hline
\end{tabular}

Literatürde Enneagram ile Müşteri Bağlılığı arasında bir çalışmaya rastlanmamıştır. Ancak kişilik özellikleriyle örgütsel davranış konuları arasında bazı çalışmalar mevcuttur. Coşkun vd. (2018) çalışmalarında Enneagram Kişilik özelliklerinin \% 95 güven düzeyinde yatırımcı davranışlarını istatistiki olarak anlamlı bir şekilde farklılaştığını ileri sürmüştür. Ferhat (2018) çalışmasında Beş Temel Kişilik Özellikleri ve alt boyutları Dışadönüklük, Uyumluluk, Sorumluluk, Duygusal İstikrarlılık ve Deneyime Açıklık ile İç-Dış Kontrol Odaklılık davranışları arasında istatistiksel olarak anlamlı bir ilişki olduğunu ifade etmiştir. Şeyma Erçin (2018) çalışmasında Enneagram Tip-7'nin sağlık sorumluluğu, fiziksel aktivite, tinsellik ve stres yönetimi alt ölçeklerinden en yüksek puanı aldığını iddia etmiştir. Makas Oral (2017) çalışmasında Enneagram Tip4'ün gelecekte depresyon gelişme ihtimaline karşı yakından izlenmesi gerektiğini iddia etmiştir. Komassi vd. (2016) çalışmalarında Enneagram Tip-1 ve Tip-5 kişilik tiplerinin cinsiyete göre anlamlı şekilde farklılaştığını ileri sürmüştür. Pesen (2015) çalışmasında grafik tasarım ürünlerinin algılanmasında farklı mizaçlardaki kişilerin kendi mizaç yapılarına bağlı olarak farklı tercihlerde bulunduklarını ifade etmiştir. Aksoy (2014) çalışmasında matematik alanında üstün yetenekli öğrencilerin Enneagram 
Tip-3 kişilik tipinde olduklarını, matematik alanında üstün yetenekli olmayan öğrencilerin ise Enneagram Tip-8 kişilik tipinde olduklarını ileri sürmüştür. Kabak (2011) çalışmasında enneagram kullanılarak grup çalışmasıyla yapılan öğretimin yedinci sınıf öğrencilerine matematik öğretimi konusunda önemli bir katkının olduğunu iddia etmiştir.

\section{Sonuç ve Öneriler}

$\mathrm{Bu}$ araştırmanın gayesi Enneagram ile Müşteri Bağl1lığı arasındaki ilişkinin belirlenmesidir. Bu amaçla Kütahya ilinde serbest muhasebeci ve mali müşavirlerden muhasebe hizmeti alan 201 mükellefe gönüllülük esasına göre ulaşılmıştır. Enneagram yakın zamanlarda hem sosyal medyada hem de akademide sıklıkla duyduğumuz kavramlardan olmaya başladı. Müşteri bağlılığı ise pazarlamacıların sıklıkla üzerinde durdukları bir kavram olmayı sürdürmektedir.

Elde ettiğimiz bulgularla Enneagram kişilik özellikleri ile Müşteri Bağlılığı arasında çok zayıf-zayıf ve orta düzeyde ilişkileri (Korelasyon analizi) tespit edilmiştir. Ayrıca Enneagram kişilik özelliklerinin Müşteri Bağllığını etkilediği (Regresyon analizi) tespit edilmiştir. Müşteri Bağl1lığ 1 ile en yüksek korelasyon "Tip-7 Maceracı" ile iken en düşük korelasyon ise "Tip-2 Yardımcı" ile olduğu tespit edilmiştir.

Elde edilen bulgular neticesinde mükellef ve işletme yöneticilerine yönelik şu önerilerde bulunulabilir;

- Mükellefler ile bağlılığı yükseltecek ortak benzer değerler oluşturulması ve bunların sürdürülmesi,

- Mükellefler ile ekonomik avantajlar sağlayarak müşteri odaklı fiyatlandırılmalarda çeşitlilik sağlanması,

- Mükellefler ile ilişkilerin bozulmasının önlenmesinde finansal olarak zarar görmeyecekleri konusunda güvence sağlanması,

- Mükellefler ile iletişimlerde alternatif hizmet sağlayıcılardan farklılıklar sıklıkla vurgulanmalı,

- Mükelleflerin marka-hizmet alımlarında alternatif seçeneklerin de değerlendirilmesi konusunda bilgilendirme yapılması,

- Mükelleflerle alışkanlıklarından ziyade hizmet sunumundaki avantajların etkileri üzerinden vurgu yapılması önerilebilir. 


\title{
EXTENDED ABSTRACT
}

\section{Relationship Of Personality Characteristics Of Taxpayers With Customer Loyalty}

\author{
* \\ Dursun Boz - İbrahim Kardaş - Ali Altınbay \\ Dumlupinar University
}

Throughout history, there have been many thinkers and researchers who have tried to understand people's attitudes and behaviors. These thinkers and researchers have tried to categorize people through various personality and temperament traits. Origin BC. Based on 2500s, Enneagram defines human typology in 9 different ways. Enneagram personality typologies also play an important role in understanding human's emotions, thoughts and behaviors and possible psychological based reactions. It tries to understand the differentiation of the physiological and mental characteristics of the human from other people in the communication that it will establish with its environment. Customer loyalty plays a key role in understanding consumer demands and expectations. As a result of the competition created by globalization and the development of advanced technologies, businesses have had to become enterprises that produce products / services beyond the wishes and expectations of consumers rather than the ones that sell what they produce. Customer loyalty in this competition has forced current customers to develop policies for the company's products / services.

\section{Enneagram}

Personality and temperament have been the focus of attention of researchers trying to understand and explain human behavior throughout human history. Various classifications have been made by developing theories on personality and temperament from Hippocrates to presentday researchers (Clark, 2005, p.506). The most important studies on these classifications are the theories beginning with the age of enlightenment, examining the psycho-social aspects of people and trying to understand 
their attitudes and behaviors. Although psychology has many personality theories, Freud's psychoanalytic theory extensively, Cattell and Norton's feature theory, Maslow and Rogers' self-theory, and Erikson and Jung's socio-psychological theory frequently examine (İnanç and Yerlikaya, 2002, p.54). In this context, Enneagram was formed by a modern synthesis of these wise traditions; it is a new personality model that tries to define and examine different features and functions in human psychology through different systematic personality types (Pesen, 2015, p.40). Enneagram, which has been influenced by psychology and philosophy in the historical process, is to evaluate the differences in the way people perceive the world, view the world and react to them with 9 different personality types (Matise, 2007, p.39). These personality types can be summarized as follows;

Type -1 Perfectionist: In the Enneagram personality typology, people who carry the "Type-One iz temperament want both himself and everything to be perfect as they should be". Honest, accurate, consistent and virtuous by giving importance, they make special efforts to provide it (Palmer, 2006, p.60).

Type-2 Charitable: People who can show their love and interest frequently, please people, are generous, possessive structure. They are people who empathize in a healthy way, who have compassion and share the feelings, thoughts and feelings of others (Maitri, 2001).

Type-3 Successful: Persons with this personality type are adaptive, ambitious, very talented and image conscious. Type-3s, they value their work, how attentive they are, they know that they are effective and presentable devote themselves to a task given to all self (Palmer, 2006, p.168).

Type-4 Original-Individual: Persons with this personality typology are those who are able to analyze their feelings and thoughts, are aware of themselves, are in contact with their emotions and inner impulses and seek their selves. They are sensitive to both themselves and others, intuitive, thoughtful, compassionate, respectful and people who care not to break people (Karabulut, 2007, p.79). 
Type-5 Researcher: Persons with this personality typology are capable of observing with extraordinary perception and understanding. Those of this type often have intellectually mindful, curious and in-depth intelligence. Values that strengthen these people; know, understand, learn and wisdom (Pesen, 2015, p.48).

Type-6 Interrogator: People with this personality typology evoke strong emotional reactions to other people. They are generally friendly, attractive, playful and leave people satisfied and grateful. Other people want to support them with affinity towards people with this personality structure (Pesen, 2015, p.49-50).

Type-7 Adventurous-Willing: Persons with this personality typology are very open to the outside, free-spirited, responsive, and very eager for their experiences, and have a strong tendency to the world of objects and senses. They respond to natural and sudden developing events, adventurous and happy people from every experience (Karabulut, 2007, s.109110).

Type-8 Challenging: Persons with this personality typology are confident, assertive and powerful people who have learned to defend and resist themselves in getting what they need and want. Axiom man is willing, self-confident has internal energies (Maitri, 2001).

Type-9 Compromise: Persons with this personality typology construct their physical needs, their lives, their inner peace and tranquility they think are indispensable. It tends to stay away from all kinds of factors that may harm this situation, conflict and non-compliance, or to postpone such situations (Maitri, 2001).

\section{Customer Loyalty}

In the historical development process, marketing has led to the development and change of consumer wishes and expectations. In this process, businesses have tried to match their marketing strategies with consumer demands and expectations. Nowadays, marketing is focused on 
the saturation of consumer demands and expectations rather than selling the goods and services produced. In this context, customer satisfaction and customer loyalty have started to gain importance. The goal of the business is to realize the importance of understanding the consumer wishes and expectations, which are no longer the optimal profit (Özgüven, 2010, p.58). Customer loyalty can be defined as the tendency, desire and actions of the customer to choose the same business / store with the usual frequency in order to buy the same product / brand at the time he / she has the right to choose or to solve the needs he needs (Odabaş1, 2000).

The aim of this study is to determine the relationship between Enneagram and Customer Loyalty. For this purpose, the 201 taxpayer who received accounting services from certified public accountant and financial advisor in Kütahya province was reached on a voluntary basis. Enneagram has recently become one of the concepts we often hear on both social media and academia. Customer loyalty remains a concept that marketers often emphasize. Our findings revealed very weak-weak and moderate relationships between Enneagram personality traits and customer loyalty. In addition, Enneagram personality traits have been found to affect both Customer Loyalty and its sub-factors. The highest correlation with customer loyalty was found to be with "Type-7 adventurer" while the lowest correlation was with "Type-2 helper".

\section{Kaynakça / References}

Akgül A. ve Çevik, O. (2005). İstatistiksel analiz teknikleri-SPSS'te işletme yönetimi uygulamaları. Ankara:Emek Ofset Ltd.Şti.,

Aksoy, E. (2014). Matematik alanında üstün yetenekli ve zekalı öğrencilerin bazı değişkenler açısından veri madenciliği ile belirlenmesi. Yayınlanmamış Yüksek Lisans Tezi, Dokuz Eylül Üniversitesi, Eğitim Bilimleri Enstitüsü, İzmir.

Barutçu, S. (2007). GSM sektöründe müşteri bağlllığı: Pamukkale Üniversitesi öğrencilerinin GSM operatörlerine bağlllıkları ve bağlılıklarını etkileyen faktörler. Afyon Kocatepe Üniversitesi İ.İ.B.F. Dergisi, 9(1), 349-372. 
Bektaş, H. ve Aydın, M. (2018). Müşteri bağlllı̆̆ının ölçülmesi: Cep telefonu pazarı üzerine bir uygulama. Atatürk Üniversitesi İktisadi ve İdari Bilimler Dergisi, 32(3), 773-191.

Bowen J. T. ve Shoemaker, S. (1998). Loyalty: A strategic commitment. Cornell Hotel and Restaurant and Administration Quarterly, 12-25.

Büyüköztürk, Ş. (2007). Sosyal bilimler için veri analizi el kitabı. (7. Bsm), Ankara: Pegem Akademi Yayıncllık.

Caruana, A. (2002). Service loyalty: The effects of service quality and the mediating role of customer. European Journal of Marketing, 36(7), ss. 811-828.

Clark, L. A. (2005). Temperament as a unifying basis for personality and psychopathology. Journal of Abnormal Psychology, 114(4), 505-521. doi:10.1037/0021-843X.114.4.505.

Coşkun, Y., Demir, S. ve Işık, İ. (2018). Investigation of investor behaviors in terms of behavioral finance: The case of Nazilli. Journal of Current Researches on Social Sciences, 8 (4), 1-32.

Ferhat, M. (2018). Beş temel kişilik boyutunun iç/dış kontrol odaklılık davranışları üzerindeki etkisi. Yayınlanmamış Yüksek Lisans Tezi, İstanbul Ticaret Üniversitesi, SBE., İstanbul.

Field, A. (2007). Discovering statistics using SPSS. Sage Publications Ltd., UK: London.

Gürbüz, S. ve Şahin, F. (2014). Sosyal bilimlerde araştırma yöntemleri. (1.Bsm), Ankara:Seçkin Yayıncllık.

Güriş, S. ve Çağlayan, E. (2005). Ekonometri. İstanbul:Der Yayınları.

İnanç, B.Y. ve Yerlikaya, E.E. (2002). Kişilik kuramları. Ankara:PEGEM Akademi..

Kabak, S. (2011). Enneagramın 7.sınıf matematik öğretiminde grup çalı̧masına etkisi üzerine bir araştırma. Yayınlanmamış Yüksek Lisans Tezi, Dokuz Eylül Üniversitesi, Eğitim Bilimleri Enstitüsü, İzmir.

Kalaycı, Ş. (2010). SPSS uygulamalı çok değişkenli istatistik teknikleri. (5.Bsm), Ankara:Asil Yayın Dağıtım,

Karabulut, Y. (2007). Yeni kişilik teorisi enneagram ve din psikolojisi açısından kullanım alanları. Yayınlanmamış Yüksek Lisans Tezi,Marmara üniversitesi sosyal bilimler enstitüsü. İstanbul. 
Komasi, S., Soroush, A., Nazeie, N., Saeidi, M., ve Zakiei, A.E (2016). Enneagram of personality as an effective model in the prediction of the risk of cardiovascular diseases: A case-control study. J Cardiothorac Med., 4(3), 468-473.

Makas-Oral, Y.N. (2017). Depresyon hastalarında kişilik tipi özellikleri. Yayınlanmamış Uzmanlık Tezi, Atatürk Üniversitesi Tıp Fakültesi Aile Hekimliği Anabilim Dalı, Ankara.

Matise, M. (2007). The enneagram an innovative approach. Journal of Professional Counseling: practice, theory, and research, 35(1), 38-58.

Maitri, S. (2001). The spiritual dimension of the enneagram: Nine faces of the soul. USA: Tarcher.

Nakip, M. (2006). Pazarlama araştırmaları teknikler ve uygulamalar. Ankara:Seçkin Yayınevi,

Odabaşı Y. (2000). Müş̧teri ilişkileri yönetimi. İstanbul:Sistem Yayıncllı,

Özeren, U. (2017). Yarın, bugünün içinde yaşanır. Dokuz tip mizaç modeli [Blog yazıs1]. $\quad 29.05 .19 \quad$ tarihinde http://ekampus.orav.org.tr/blogger/ugurozeren/page/43605/yarin-bugununicinde-yasanir----dokuz-tip-mizac-modeli-- adresinden erişilmiştir.

Özgüven, N. (2010). İşletmelerin uyguladıkları sosyal sorumluluk kampanyalarının müşteri bağlılı̆̆ yaratmaktaki rolü ve bir uygulama. Yayınlanmamış Doktora Tezi, Dokuz Eylül Üniversitesi, Sosyal Bilimler Enstitüsü, İzmir.

Palmer, H. (2006). Ruhun aynası enneagram'a yansiyan insan manzaraları. İstanbul:Kaknüs Yayınları,

Pesen, S.R. (2015). Grafik tasarım göstergelerinin algılanmasında kişilik faktörünün enneagram modeline göre incelenmesi. Yayınlanmamış Yüksek Lisans Tezi, İstanbul Kemerburgaz Ünïversïtesï, Sosyal Bilïmler Enstitüsü, İstanbul.

Selvi, S. M. ve Ercan, F. (2006). Otel işletmelerinde müşteri sadakatinin değerlendirilmesi: İstanbul'daki beş yıldızlı otel işletmelerinde bir uygulama. Balikesir Üniversitesi, Sosyal Bilimler Enstitüsü Dergisi, 9(15), 159-188.

Subaş A. ve Çetin M. (2017). Enneagram kişilik ölçeğinin geliştirilmesi: Güvenirlik ve geçerlilik çalışması. Sosyal Bilimler Dergisi 4(11), 160181. 
Şeyma-Erçin, H. (2018). Sağlıklı yaşam biçimi davranışları ile enneagram kişilik tipleri arasındaki ilişkinin değerlendirilmesi. Yayınlanmamış Uzmanlık Tezi, Yıldırım Beyazıt Üniversitesi Tıp Fakültesi Aile Hekimliği Anabilim Dalı, Ankara.

Taştan, K. (2019). Development and validation of a personality type inventory based on enneagram. Konuralp Tip Dergisi, 11(1), 112-118.

\section{Kaynakça Bilgisi / Citation Information}

Boz, D., Kardaş, İ. ve Altınbay, A. (2019). Muhasebe hizmeti alan mükelleflerin kişilik özelliklerinin müşteri bağl1lığı ile ilişkisi. OPUSUluslararası Toplum Araştırmaları Dergisi , 14(20), 1501-1527. DOI: 10.26466/opus.612220 